\title{
Comparison of the Development of the Rhotic in Children Acquiring British and American English
}

\author{
$\mathrm{Jia} \mathrm{Shi}^{1}$ \\ ${ }^{1}$ Capital Normal University High School,Beijing,Haidian District100048, China \\ * Jia Shi. Email: shijiatougao@163.com
}

\begin{abstract}
This paper reports on a study into the acquisition of rhotic phonemes by children acquiring British and American English, and compares the results with those obtained earlier for bilingual children acquiring Welsh and English. It concentrates on the acquisition of the rhotic consonants, that is, the differences in the patterns of realization of $/ \mathrm{r} /$ between a North American child Julia and a British child Jane. The study demonstrates a wide range of substitutions of $/ r$ / made by the North American child Julia and the British child Jane is consistent with the results reported for Welsh-English bilingual children. We also found that the older the children become, the less variation is found in the substitutions used for approximant $/ \mathrm{r} /$. It is also shown that there is an acoustic reason for the choice of the commonest of them. While for Welsh and English bilingual children the sounds are clearly different, neither the trill nor the approximant demonstrate $100 \%$ accurate usage even in the oldest age group of subjects $(4 ; 6-5 ; 0)$ (although the approximant does approach $90 \%$, same as for North American and British children). Therefore, they belong to the group of consonants acquired last in their respective languages.
\end{abstract}

Keywords: language acquisition, rhotic, development, British English, American English

\section{INTRODUCTION}

Nowadays, English is the most widely spoken language in the world. We all know that the accents in America and the UK are quite different from each other. The main reason why people find them different and use the word 'accent' to tell them apart is because of the articulation. The most well-known difference is the $/ \mathrm{r} /$ sound. Rhotic refers to the $/ \mathrm{r} /$ sound, the words which having all the R's pronounced before a consonant, or it can say rhotic is a dialect of English in which the $/ \mathrm{r} /$ is pronounced at the end of a syllable or before a consonant. The first known use of rhotic was in1960s from Greek rhot-. In addition, the history and etymology for rhotic is rhot- (in RHOTACISM or RHOTACIZE). In Cambridge Dictionary rhotic is somewhat a word that used to refer to a type of English, in which an $/ \mathrm{r} /$ is pronounced in all situations where there is an " $r$ " in spelling. The definition of rhotic in Merriam-Webster can be understood from phonetics: it means of, relating to, having, or being an accent or dialect in English in which an $/ \mathrm{r} /$ sound is retained before consonants (as in pronouncing hard and cart) and at the end of a word (as in pronouncing car and far) or in phonetics, of a vowel: influenced in coloring by an adjacent $/ \mathrm{r} /$ sound. The definition of rhotic by Oxford Dictionary is relating to or denoting a dialect or variety of English in which $r$ is pronounced before a consonant (as in hard) and at the ends of words (as in far). From a linguistic perspective, rhotic consonants, or "R"-like sounds, are non-lateral liquid consonants. And it is of great research value, this class of sounds is difficult to characterize phonetically, though most of them share some acoustic peculiarities, most notably a lowered third formant in their sound spectrum. However, "being r-like" is a strangely elusive feature, and the very same sounds that function as rhotics in some systems may pattern with fricatives, semivowels or even stops in others.

We know that /r/ can have many phonetic realizations and, from this point of view, it is not surprising that children use so many substitutions. We know that, for example, in British English [1], the rhotic phoneme is usually realized as the alveolar approximant $[\mathrm{I}]$, but can also be realized as [r], [R] and [r]. Besides, people who speak British English perhaps use [v] on the realization of the rhotic.

The structure of this paper is as follows. It will first discuss the reason why this topic is important. Secondly, we will look at the methodology of how the data was 
collected. Finally, we will discuss the results of the research. Additionally, there is the comparison of the results to an existing study and, finally, the conclusion.

\section{BACKGROUND}

Rhotics are a kind of complex articulation, while variable for the anterior articulators, may be a feature of rhotics in general. The other linguist, Scobbie [1] also argues that rhotics are articulatory complex segments, involving an apical as well as a pharyngeal element. He thinks that this complexity is possible because of their tendency toward variation and change so that's the reason why children do not acquire them quickly or why $/ \mathrm{r} /$ sound does not show up so early in acquisition and also why it is hard for children to acquire.

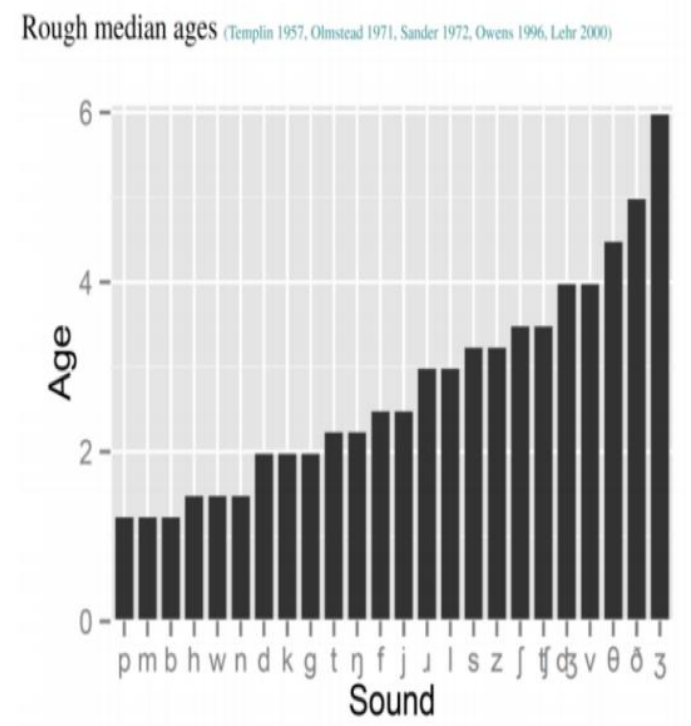

Figure 1 The tendency toward variation of children at each age. (Ryan, Kevin M. 2015. Linguistics 101 class materials. Harvard University)

The reason why I focus on this topic due to the fact that one of the major reason which cause the different accent between British and American English is the process when the children acquiring the language. For Polish, Jaworski \& Gillian [2] suggest that rhotics are complex from an articulatory point of view, and this complexity makes rhotics especially susceptible to phonetic change. Lindau [3] also agrees, saying that "[a]n actual trill realization of an $/ \mathrm{r} /$ is not as common as might be expected from descriptions of languages, where an $/ \mathrm{r} /$ is often labeled as a 'trill'. Even in languages where a possible realization is a trill, not all speakers use a trill, and the speakers that do, have tap and approximant allophones as well as the trill." For example, Widdison [3] notes that the Spanish apical vibrant is as difficult for native speakers to master as it is for nonnatives.

As a result, it will not be very surprising, as we find out, that children use so many substitutions to replace $/ \mathrm{r} /$.
That's also why this topic is significant, which gives me a lot of motivation to find the patterns of variation in the realization of rhotics in early childhood. Why we selected the children from North America and the UK for this project? This is because all English learners know that the accent of British English and American English are different, one of the key points that can help us investigate the nature of these differences is to start from the period of time when they begin to acquire English. Therefore, the children from these two places (North America and the UK) can be a powerful example. The differences in / $r$-acquisition that we may expect are quite significant and obvious but there also have some similarities between them.

\section{METHOD}

In this research, we going to study the English part of the rhotics. To find out the reasons why the accent between British and American English are different. We used PhonBank (https://phonbank.talkbank.org/access/), an online repository of annotated phonological data that includes data from first language acquisition by children from around the world, and then selected the data from children from North America and the UK, and collected all of the information of $/ r /$ sound words.Then, we categorized the positions of/r/ in each word. Additionally, we summarized the results in order to find the differences or similarities between the positions of /r/. Finally, we made a comparison of the North American child Julia and British child Jane, and also compared their results to those available in the literature [4-6]

The information about children:

1Julia: 1;05.17 3;06.18 Female

2Jane: $1 ; 5$ to $3 ; 7$ Female

We use these abbreviations to describe possible positions of /r/

Word-final $/ \mathrm{r} /=\mathrm{WF}$

Word-initial /r/=WI

Word-medial $/ \mathrm{r} /=($ after a vowel and before another vowel)= WM1

Word-medial $/ \mathrm{r} /=($ after a vowel and before a consonant $)=\mathrm{WM} 2$

Word-medial $/ \mathrm{r} /=($ after a consonant and before a vowel $)=\mathrm{WM} 3$

\section{RESULTS}

We found out from observation: 


\subsection{For North American Child-Julia}

Timeline of the different position of $/ \mathrm{r} /$ that first appear correctly: $\mathrm{WI}=\mathrm{WM} 3>\mathrm{WM} 1>\mathrm{WM} 2>\mathrm{WF}$

The earliest position to appear, the lastest position to appear.

First, /r/ appears word-initially and word-medially that after a consonant before a vowel, then /r/ appears word-medially that between vowels, besides $/ \mathrm{r} /$ appears word-medially that after a vowel and before a consonant, finally $/ \mathrm{r} /$ appears word-finally for North American child Julia.

If the observed results were plotted as a table, they would look like the following Table 1:

Table 1 The results of Julia.

\begin{tabular}{|l|l|l|}
\hline Position & $\begin{array}{l}\text { First time to } \\
\text { appear the } \\
\text { correct } \\
\text { pronunciation }\end{array}$ & Substitutions \\
\hline WF & $|3 ; 01.28|$ & $\begin{array}{l}\text { Vowel; extended } \\
\text { vowel; approximant }\end{array}$ \\
\hline WI & $|1 ; 08.14|$ & $\begin{array}{l}\text { Approximant;affricate; } \\
\text { fricative; nasal stop; } \\
\text { plosive ;vowel }\end{array}$ \\
\hline WM1 & $|2 ; 09.13|$ & $\begin{array}{l}\text { Extended vowel; } \\
\text { plosive; approximant }\end{array}$ \\
\hline WM2 & $|2 ; 11.15|$ & $\begin{array}{l}\text { Extended vowel; } \\
\text { vowel; } \\
\text { approximant;only } \\
\text { once the nasal stop }\end{array}$ \\
\hline WM3 & $|1 ; 08.14|$ & $\begin{array}{l}\text { Approximant; } \\
\text { affricate; nasal stop; } \\
\text { plosive ;vowel }\end{array}$ \\
\hline
\end{tabular}

As it can be seen from the table. To begin with, in the position of WF, the earliest occurrence time is $|3 ; 01.28|$.The substitutions are vowel; extended vowel and approximant( such as: w; ə; I; っ; ৩; з; っ:; j; a:; æ...). Secondly, in the position of WI, the earliest occurrence time is|1;08.14|.The substitutions are approximant; affricate; fricative ;nasal stop; plosive and vowel( such as: $v ; \mathrm{w} ; \mathrm{v} ; \mathrm{b} ; \mathrm{n} ; \mathrm{d} ; \mathrm{j} ; \mathrm{\partial} ; \mathrm{m} ; \mathrm{d} 3 . .$.$) . Besides, as for the$ position of WM1, the earliest occurrence time is $2 ; 09.13$. The substitutions are extended vowel; plosive; approximant (such as: $\varepsilon:$ j; w; ?...). Additionally, as for the position of WM2, the earliest occurrence time is $2 ; 11.15 \mid$. The substitutions are extended vowel; vowel; approximant and only once the nasal stop (such as: $3 ;$ ə; a; $\Lambda ; v ; \mathrm{j} ;$ ө: $;$ : ; n...). Finally, in the position of WM3, the earliest occurrence time is $|1 ; 08.14|$. The substitutions are approximant; affricate; nasal stop; plosive; vowel( such as:æ ;w; $\Lambda$; ; n; $2 ; \widehat{\mathrm{t} \int}$; i...) [7-9].

\subsubsection{The Observation of The American Child- Julia}

Timeline of the different position of $/ r /$ that first appear correctly:

\section{$\mathrm{WI}=\mathrm{WM} 3>\mathrm{WM} 1>\mathrm{WM} 2>\mathrm{WF}$}

First, /r/ appears word-initially and word-medially that after a consonant before a vowel, then $/ \mathrm{r} /$ appears word-medially that between vowels, besides $/ \mathrm{r} /$ appears word-medially that after a vowel and before a consonant, finally /r/ appears word-finally for North American child Julia.

Both the WI and the WM3 are the earliest positions for Julia to acquire correctly.

The hardest position for Julia to acquire is the final $/ \mathrm{r} /$, which means this position of $/ \mathrm{r} /$ appears the latest.

The WM1 between vowels are always substituted by extended vowel; approximant and sometimes by plosive-?.

\subsection{For British Child-Jane}

Timeline of the different position of $/ r /$ that first appear correctly:

\section{$\mathrm{WM} 3>\mathrm{WI}>\mathrm{WM} 1$}

The earliest position to appear, the lastest position to appear.

First, /r/ appears word-medially that after a consonant before a vowel, then $/ \mathrm{r} /$ appears word-initially, finally $/ \mathrm{r} /$ appears word-medially that between vowels. The reason why both WF and WM2 are not appear in whether the timeline or the comparison is due to the fact that British English is non-rhotic,the only situation that $/ \mathrm{r} /$ can be acquire is followed by another vowel for British child Jane.

If the observed results were plotted as a table, they would look like the following Table 2 .

Table 2 The results of Jane.

\begin{tabular}{|l|l|l|}
\hline Position & $\begin{array}{l}\text { First time to } \\
\text { appear the } \\
\text { correct } \\
\text { pronunciation }\end{array}$ & Substitutions \\
\hline WF & $|2 ; 06.08|$ & $\begin{array}{l}\text { Vowel; just } \\
\text { missing }\end{array}$ \\
\hline WI & $|2 ; 02.07|$ & $\begin{array}{l}\text { Plosive; } \\
\text { approximant; } \\
\text { fricative }\end{array}$ \\
\hline
\end{tabular}




\begin{tabular}{|l|l|l|}
\hline WM1 & $|2 ; 03.13|$ & $\begin{array}{l}\text { Extended } \\
\text { vowel; plosive; } \\
\text { approximant }\end{array}$ \\
\hline WM2 & $|2 ; 10.18|$ & $\begin{array}{l}\text { Vowel; } \\
\text { extended } \\
\text { vowel;only } \\
\text { once the nasal } \\
\text { stop }\end{array}$ \\
\hline WM3 & $|2 ; 00.09|$ & just missing \\
\hline
\end{tabular}

As it can be seen from the table. To begin with, in the position of $\mathrm{WF}, / \mathrm{r} /$ is not realized in this enviroment in British English mainly because British English is non-rhotic which means no $/ \mathrm{r} /$ pronounced when it is immediately after a vowel and not followed by another vowel so the final $/ \mathrm{r} /$ is not realized in this environment in British English but it has some exceptions. We still recorded the earliest occurrence time is $2 ; 06.08 \mid$. The substitutions are vowel or just missing(ə), The exceptions are:|2;06.08|here(here it is);|3;07.10|are(are I); $3 ; 08.17 \mid$ for(for it); $3 ; 10.03 \mid$ are(are his $\rightarrow$ or $1 \mathrm{Z}$, the $/ \mathrm{h} / \mathrm{is}$ missing). Secondly, in the position of WI, the earliest occurrence time is $|2 ; 02.07|$.The substitutions are plosive; approximant and fricative( such as: $b ; v ; \beta \ldots$ ). Besides, as for the position of WM1, the earliest occurrence time is $2 ; 03.13 \mid$.The substitutions are extended vowel; plosive and approximant( such as:a; w; $\mathrm{i}$ :...). Additionally, as for the position of WM2, /r/ is not realized in this environment in British English as well. This position is always be ignored and always be substituted by the extended vowel before $/ \mathrm{r} /$ or just replaced by /ə/.But! In $|2 ; 10.18|$ the word airport is the only correct one that the $/ \mathrm{r} /$ haven't be substituted by the extended vowel before $/ r$ / or just replaced by /ə/.So the earliest occurrence time is $|2 ; 10.18|$.The substitutions are Vowel; extended vowel and only once the nasal stop( such as: ə; ; ə: ; n...). The reason why British child Jane can pronounce the word airport(Eərəoplo:t) correctly is because the $/ r /$ is between two vowels. That's the only situation that $/ \mathrm{r} /$ can be pronounced in this position. Finally, in the position of WM3, the earliest occurrence time is|2;00.09|.The substitutions are just missing.

\subsubsection{The Observation of The British Child-Jane}

British English is non-rhotic which means no /r/ pronounced when it is immediately after a vowel and not followed by another vowel so the final $/ r /$ is not realized in this environment in British English [10].

Timeline of the different position of $/ \mathrm{r} /$ that first appear correctly:

\section{$\mathrm{WM} 3>\mathrm{WI}>\mathrm{WM} 1$}

First, /r/ appears word-medially that after a consonant before a vowel, then $/ \mathrm{r}$ / appears word-initially, finally $/ \mathrm{r} /$ appears word-medially that between vowels.The reason why both WF and WM2 are not appear in whether the timeline or the comparison is due to the fact that British English is non-rhotic,the only situation that $/ \mathrm{r} /$ can be acquire is followed by another vowel for British child Jane.

After $|2 ; 02.07|($ include $2 ; 02.07 \mid$ ) all the WI are pronounced correctly, except only one time of |2;06.20|room .

Unlike with the American child Julia, WM3 are almost always ignored (missing) until Jane acquired the correct realization of $/ \mathrm{r} /$ and this position of $/ \mathrm{r} /$ appears the earliest.

Especially for WI, the acquisition of UK Jane is more stable than NA Julia.

We can understand by these exceptions of the $\mathrm{WF}$ (the words which can be pronounce correctly of this position are all preposition or verb) about why British English is non-rhotic,the only situation that $/ \mathrm{r} /$ can be acquire is followed by another vowel [11].

\subsection{The Comparison of NA Julia and UK Jane}

For NA Julia, the initial /r/ is the easiest and earliest position to acquire. For UK Jane, this is the position that can be $100 \%$ correct. It is the most stable position to be pronounced correctly after|2;02,07|(except only one time).

The children who are approaching 2 years old or are over 2 years of age can pronounce the $/ r /$ sound correctly.Much less variation is found with the substitutions used for approximant $/ r /$ same as the Welsh-English bilingual children when they acquire English /r/).

NA Julia acquired/r/ (in allpositions) earlier than UK Jane (just based on the available data. We know the ability for children to acquire language(s) depends on many other factors such as their physical health, their growing environment and so on).

For each position of $/ \mathrm{r} /$ :

WF is the hardest position for children to acquire.( here we only refer to NA Julia's data, because this position for UK Jane is not realized in British English)

For WM1, we can conclude that when children substituted WM1 with other sounds, they did so because they prefer to insert a consonant between the vowels, and $/ r /$ is not the easiest.

WM2 is the second hardest position for children to acquire. Here, $/ \mathrm{r} /$ is always substituted by (extended)vowels before / $\mathrm{r} /$ or just replaced by vowels( actually here we only refer to NA Julia's data 
too cause this position for UK Jane is not realized in British English ).

WI is the easiest position for children to acquire and WM3 is the second easiest one.

For Welsh-English bilingual children the WI in English is also the easiest position for them to acquire. Same as for the NA child Julia and UK child Jane, WI is the easiest position for them to acquire. Although the WI and WM3 both appear the earliest for Julia and WM3 is the earliest position that appear for Jane,I still chose to say that the WI is the easiest position for NA Julia and UK Jane to acquire mainly because the first time WI / $r$ / appears in Julia's speech is $|1 ; 08.14|$ and the second time was in $|2 ; 04.25|$, for UK Jane the WI first acquire in $|2 ; 02.07|$ and the only exception is when she was in $|2 ; 06.20|$. But as for WM3, the first time to acquire this position of $/ \mathrm{r} /$ for NA Julia is in $|1 ; 08.14|$ and the second time that it appear was in $|2 ; 07.21|$, for UK Jane this position of / $\mathrm{r} /$ was first appear in $|2 ; 00.09|$ and the second time was in $|2 ; 03.26|$. So, for both Julia or Jane, the time between the first time and the second time of pronouncing the correct /r/ for WI are shorter than WM3, which means that, though the WM3 appeared the earliest, it's still not as easy or stable as WI That's why I conclude that WI is the easiest for both NA Julia and UK Jane or even Welsh-English bilingual children and the WM3 is the second easiest for children to acquire.

Table 3 The acquisition of the Rhotic Consonants.

\begin{tabular}{|l|c|c|c|}
\hline \multicolumn{2}{|c|}{ Acquisition of /d/ } & \multicolumn{2}{|c|}{$\%$ correct /d/ } \\
\hline Groups & Position & $\begin{array}{l}\text { Welsh } \\
\text { dominant }\end{array}$ & $\begin{array}{l}\text { English } \\
\text { dominant }\end{array}$ \\
\hline \multirow{2}{*}{ Group A } & $\mathrm{I}$ & $40 \%$ & - \\
\cline { 2 - 4 } & $\mathrm{M}$ & $58 \%$ & - \\
\hline Group B & $\mathrm{I}$ & $48 \%$ & $76 \%$ \\
\cline { 2 - 4 } & $\mathrm{M}$ & $34 \%$ & $56 \%$ \\
\hline \multirow{2}{*}{ Group C } & $\mathrm{I}$ & $76 \%$ & $74 \%$ \\
\cline { 2 - 4 } & $\mathrm{M}$ & $83 \%$ & $61 \%$ \\
\hline \multirow{2}{*}{ Group D } & $\mathrm{I}$ & $74 \%$ & $85 \%$ \\
\cline { 2 - 4 } & $\mathrm{M}$ & $75 \%$ & $90 \%$ \\
\hline \multirow{2}{*}{ Group E } & $\mathrm{I}$ & $89 \%$ & $87 \%$ \\
\cline { 2 - 4 } & $\mathrm{M}$ & $67 \%$ & $45 \%$ \\
\hline
\end{tabular}

(This table is taken from The acquisition of the Rhotic Consonants by Welsh-English bilingual children Martin J. Ball, Nicole Müller and Siân Munro.)

\subsection{The hypothesis}

The $/ r /$ are the easiest to pronounce when it is not surrounded by other consonants.

The hypothesis of consonants: if a consonant is before $/ \mathrm{r} /$, it won't influence the $/ \mathrm{r} /$ sound, but when a consonant is after the $/ r /$, that will slow down its acquisition. Similarly, when $/ \mathrm{r} /$ is before a vowel, that does not affect acquisition. Sometimes, children will create $/ r$ / sound by themselves when the word do not even contain the $/ r /$ sound, for example: for North American child Julia, when she was in $|3 ; 06.03|$ she pronounced juice into dzxijus (Julia create a /r/ sound by herself) This hypothesis explains why WM3 appear firstly for both NA Julia and UK Jane and why WM2 is hard for children to acquire) $[12,13]$

Examples to verify the hypothesis:

When Julia was $|3 ; 04.16|$ she changed the word [everything] into exij $\theta \tilde{I}$ y. The /r/ of the word [everything] belongs to WM3 but she changed the /r/ into WM1.

Also, when Julia was $|3 ; 04.16|$ she changed the word [prezzie] into $ı$ :zij. The $/ \mathrm{r} /$ of the word [prezzie] also belongs to WM3 but she changed the /r/ into WI.

These two examples illustrate that the first hypothesis is on the right track - it is easy to pronounce

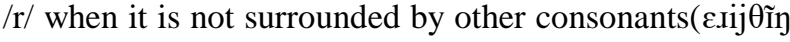
and $ı \varepsilon: z i j)$.As for the second hypothesis (when there's a consonant before $/ r /$, it will not affect the correct pronunciation of $/ \mathrm{r} /$ ), there is likely to be a phonetic reason for why children ignore the consonants before $/ \mathrm{r}$ / I hypothesize that's why WM3 appear firstly for both NA Julia and UK Jane and why WM2 is hard for children to acquire.

\section{CONCLUSION}

We chose this topic, acquisition of rhotics, because according to Chabot [4], rhotics in some languages are as difficult for native speakers to master as it is for nonnatives. Similarly, Scobbie [1] argues that rhotics are articulatory complex segments, involving an apical as well as a pharyngeal element, and this complexity is a possible because of their tendency toward variation and change so that's the reason why children do not acquire them quickly or why /r/ sound does not show up so early in acquisition and also why it is hard for children to acquire. In addition, we selected the children from North America and the UK for this project because all English learners know that the accent of British English and American English are different, and one of the perspectives that can help us to investigate that is the case is to look at the acquisition of both varieties.

\section{REFERENCES}

[1] Scobbie, James M. 2006. (R) as a variable. In Keith Brown (ed.), Encyclopedia of language \& linguistics, Second Edition 10. 337-344. Oxford: Elsevier. DOI: https://doi.org/10.1016/B0-08044854-2/04711-8

[2] Jaworski, Sylwester \& Edward Gillian. 2011. On the phonetic instability of the Polish rhotic /r/. Poznań 
Studies in Contemporary Linguistics 47(2). 380398. DOI: https://doi.org/10.2478/psicl-2011-0022

[3] Widdison, Kirk A. 1997. Variability in the lingual vibrants: Changes in the story of $/ \mathrm{r} /$. Language \& Communication 17(3). 187-193. DOI:https://doi.org/10.1016/S02715309(97)00011-6

[4] Chabot, Alex. 2019. What's wrong with being a rhotic?

[5] The acquisition of the Rhotic Consonants by WelshEnglish bilingual children Martin J. Ball, Nicole Müller and Siân Munro

[6] Foulkes, Paul \& Gerry Docherty. 2001. Variation and change in British English. In Hans Van de Velde \& Roeland van Hout (eds.), 'r-atics: sociolinguistic, phonetic and phonological characteristics of /r/, 27-43. Brussels: ILVP

[7] Language \& linguistics, Second Edition 10. 337-344. Oxford: Elsevier. DOI: https://doi.org/10.1016/B008-044854-2/04711-8

[8] Templin, M. (1957). Certain language skills in children: their development and interrelationships(Monograph Series No. 26). Minneapolis: University of Minnesota, The Institute of Child Welfare

[9] Olmstead, D. L. (1971).Out of the Mouths of Babes, Mouton, The Hague.

[10] Sander, E. K. (1972). When are speech sounds learned?. Journal of speech and hearing disorders, 37(1), 55-63.

[11] Owens, R.E. (1996) Language development: An introduction. Boston: Allyn and Bacon.

[12] Lehr, F. R. (2000). The sequence of speech-sound acquisition in the Letter People program. Waterbury, CT: Abrams \& Company.

[13] Boyce et al. (2016) Boyce, Suzanne E., Sarah M. Hamilton \& Ahmed Rivera-Campos. 2016. Acquiring rhoticity across languages: An ultrasound study of differentiating tongue movements. Clinical Linguistics and Phonetics 30(3-5). 174-201. 